\title{
Unpacking Mathematics for Teaching: A Study of Preservice Elementary Teachers' Evolving Mathematical Understandings and Beliefs
}

\author{
Ann Kajander \\ Lakehead University
}

\begin{abstract}
This study examined the mathematical understandings and beliefs held by preservice elementary teachers in a mathematics methods course taken as part of a one year teacher certification program, and reexamined these characteristics at the end of the course. The notion of 'understanding mathematics for teaching' was examined in a way that might begin to support the work of mathematics educators working with such preservice teacher candidates. Preservice teacher beliefs about what is important in mathematics learning and therefore the teaching of it are examined along with mathematics understanding at both procedural and conceptual levels. The goal was to shed some light on how initial understanding and beliefs about mathematics teaching co-exist, and how these might develop during a preservice teacher education program.
\end{abstract}

A growing body of research argues that teacher knowledge of mathematics is an important factor for student success (Adler \& Davis, 2006; Ball, 2000; Ball, Hill \& Bass, 2005; Hill, Rowan \& Ball, 2005). Studies have also highlighted struggles new teachers may face in their own classrooms to overcome earlier notions of how mathematics should be taught, even after being exposed to alternatives in their preservice programs (Ambrose, 2004; Ensor, 2001; Raymond, 1997). Beliefs and values about mathematics itself may play a role in influencing teacher classroom behaviour, especially decisions about what types of questions to ask, how deeply to probe, and how much methodological direction to impose (Kajander, 2004; McDougall et al., 2000). Teachers' attitudes also in turn impact students (Bishop, Clarke, Corrigan \& Gunstone, 2006; Schommer-Aikins \& Hutter, 2005; Ruffell, Mason \& Allen, 1998). It is also argued that teacher mathematics knowledge and beliefs are intrinsically related (Ambrose, 2004; Stipek, Givven, Salmon \& MacGyvers, 2001) and are likely to influence one another in the process of teacher development. Hence, teacher knowledge and beliefs will potentially influence the quality of teaching and subsequently impact students in classrooms.

The current study examined the mathematical understandings and beliefs that preservice elementary teachers might typically bring to a mathematics methods course which is taken as part of a one year teacher certification program. These

An experienced classroom teacher, Ann Kajander is an Associate Professor of mathematics education at Lakehead University. She is passionate about supporting preservice and in-service teachers in their mathematical development. 
characteristics are re-examined at the end of the course. An initial framework is suggested for the purpose of beginning to unpack the notion of "understanding mathematics for teaching” in a way that might support the work of mathematics educators working with such preservice teacher candidates. In the study, preservice teacher beliefs about what is important in mathematics learning and teaching are examined alongside mathematical understandings at procedural and conceptual levels. This study draws on notions of understanding mathematics for teaching based on the work of Ma (1999), Ball \& Bass (2000), and Ball et al. (2005).

\section{Background}

\section{Framework}

This study is grounded in adult learning principles such as the need to consider participants' self-concerns (Loucks-Horsley, 1996) and underlying values and beliefs (Kiely, Sandmann, Truluck, 2004) which include making available the reasons for learning (Schmitt \& Safford-Ramus, 2001), encouraging active participation in learning (Kiely et al.), and encouraging self-reflection (Gusky, 2000, 2003). In my experience, preservice teachers may be insecure about their mathematical understandings and hence their self-concerns can be particularly overwhelming. Yet their initial enthusiasm and desire to become good teachers provides a strong motivation to invest energy in their own mathematical development if they see the need to do so, and thus preservice teachers may in fact be critically poised for a transformative experience as described by Kiely et al.. Making use of such golden moments may be crucial in the development of highly effective teachers of mathematics.

\section{Understanding Mathematics for Teaching}

It is well documented that effective reform-based classrooms require deeper and broader understanding of mathematics on the part of teachers (Adler \& Davis, 2006; Ball, 1990, 1991, 1996, 2000 \& 2003; Ball et al., 2005; Hill \& Ball, 2004; Greenwald, Hedges \& Laine, 1996). Such knowledge is important in teaching for understanding (Ball, 1996).

In Ma's (1999) landmark study, in-service teachers' understanding of mathematics was probed in individual cases. It was found that many US teachers were in fact able to calculate correct answers to elementary mathematical questions, but were not able to explain why the methods worked, or give an example or problem that showed their understanding of the procedure. Ma's study shows in detail how teachers may be reasonably proficient in basic mathematical procedures such as, for example, methods of multiplication or division of fractions or integers, yet may be completely unable to explain, show or justify why such methods work, which are the "profound understandings" (Ma) needed for effective teaching. Preservice elementary teacher candidates generally arrive in methods courses with largely procedural understandings of the subject (Ambrose, 2004). Since research suggests that building a conceptual understanding after a procedural approach has been encouraged can be a 
challenge for learners (Hiebert, 1999), it is necessary for participants to be deeply committed to the process and its importance.

Ball and her colleagues (for example, Ball \& Bass, 2000) have further investigated the concept of mathematical understanding for teaching. Such understanding requires teachers to be able to "unpack" previously held mathematical ideas in a way that supports their teaching in classrooms (Ball, 1991; 1996; 2000; Ball et al., 2005). Unpacked conceptually based understanding may not be something preservice teachers have had an opportunity to previously develop (Kajander, 2005).

Teachers' understanding must be conceptual in nature to allow teachers to probe student understanding, comprehend multiple student solutions and methods, and provide powerful classroom models (Hill et al., 2004). Hence, if preservice teachers arrive in teacher education programs with mathematical understandings that are largely traditional and procedural as has been suggested (Ambrose, 2004), important challenges must be faced in methods courses.

\section{Procedural and Conceptual Knowledge}

The relationship between procedural knowledge and conceptual knowledge is important in studying knowledge of mathematics for teaching (Ambrose, 2004; Hiebert, 1999; Hill et al., 2004; Lloyd \& Wilson, 1998; McCormick, 1997; Rittle-Johnson \& Kroedinger, 2002), and unpacking procedural knowledge to support the development of deeper conceptual knowledge is a particular challenge at the preservice level (Adler \& Davis, 2006).

Procedural knowledge may be thought of as a sequence of actions while conceptual knowledge is knowledge that is rich in relationships (Hiebert, 1992; McCormick, 1997), for example the relationship between appropriate physical materials such as classroom manipulatives, and written symbols such as algebraic notation. Procedural knowledge has also been described as referring to computational skills, while conceptual knowledge refers to understanding the underlying mathematical structure (Eisenhart et al., 1993). Ideally, teachers should see procedural skill and conceptual understanding as interrelated (Ambrose, 2004). Deep procedural knowledge might ultimately be connected to comprehension, flexibility and critical judgment (Star, 2005). However for the purposes of this initial discussion I will assume Hiebert's (1992) interpretation of procedural knowledge as it may describe the type of mathematical preparation typically held by incoming preservice teachers with traditional backgrounds.

\section{Connections to beliefs and values}

Deepened knowledge alone may not be sufficient for teachers to choose to teach differently from the ways in which they initially learned mathematics themselves; beliefs also appear to play a role (Ambrose, 2004; Foss, 2000; Raymond, 1997; Stipek, Givvin, Salmon, MacGyvers, 2001). Beliefs may be thought of as "the ideas people are committed to. Sometimes called core values ... beliefs shape ones' ways of perceiving and acting. ... They shape goals, drive decisions, create discomfort when violated, and stimulate on-going critique” (Loucks-Horsley, Love, Stiles, Mundry \& Hewson, 2003, p.7). 
Beliefs about the nature of learning, or epistemological beliefs, have been linked to academic learning (Schommer-Aikins, Duell \& Hutter, 2005). Schoenfeld (1983, 1985) also concluded that students' mathematical problemsolving processes are influenced by students' beliefs about the nature of mathematics. In a more recent study of middle school students, it was shown that the less students believed in quick-fix learning, the more they were likely to believe that mathematical problem solving is useful (Schommer-Aikins et al., 2005).

It is also of interest then, whether teachers who develop deeper mathematical knowledge also change their beliefs about what is important in the learning of mathematics (Kajander, 2004; Raymond, 1997), and whether such changes are resilient. In a recent study, in-service grade seven teachers who significantly increased their knowledge of mathematics for teaching during extensive professional development also increased their valuing of conceptual learning and decreased the value they placed on procedural learning in their classrooms (Kajander, Keene, Siddo \& Zerpa, 2006; Kajander \& Zerpa, 2006). Other research indicates that influencing teachers' beliefs and values may be essential to changing teachers' classroom practices (Ball, 1996; Cooney, Shealy \& Arvold, 1998; Ross, McDougall, Hogaboam-Grey, LeSage, 2003; Stipek et al., 2001).

Boaler (2000) suggests that "when students learn algorithms through the manipulation of abstract procedures, they do not only learn the algorithms, they learn a particular set of practices and associated beliefs" (p. 3). Ball (1996) indicates that the subsequent teacher development process entails "revising deeply held notions about learning and knowledge" (p. 501). A situated perspective suggests that people develop knowledge through their interactions with broader social systems (Boaler, 2000; Hoyles, 1992). Thus, preservice learning should arguably build on previous learning situated in participants' own previous classroom experiences, and should include "building on, rather than tearing down, pre-existing beliefs” (Ambrose, 2004, p. 91).

Evidence indicates that beliefs change incrementally and gradually (Ambrose, 2004; Kajander et al., 2006). A purely situated perspective (for example, see Boaler, 1999, 2000; Hoyles, 1992) would suggest that no clear relationship should be expected between a novice teacher's professed beliefs as developed during a methods course, and her subsequent teaching practices (Skott, 2001). On the other hand, if students (including teacher candidates) are, in fact, "active agents who develop their own beliefs and practices ... shaped by the communities in which they engage” (Boaler, 1999, p. 279) then more favourable results might be obtained if both the preservice environment and subsequent professional development attend as closely as possible to the realities of the classroom teaching environment.

Given the incremental nature of beliefs changes, and the pressures, context and influences of the teaching environment, it is not unexpected that a number of studies report only partial enactment of novice teachers' newly developed espoused beliefs (Ambrose, 2004; Ensor, 2001; Raymond, 1997). On the other hand, if beliefs change gradually, this might suggest that resultant changes in practice would also be gradual. Ensor reports that "school setting and the educational biography do appear to shape the ways that beginning teachers draw from their preservice courses, but not decisively" (p. 317). Hoyles (2002) 
suggests teachers can shape and change the culture in their own classroom. Hence, preservice courses need to develop "habits of mind to learn from the classroom” (Ebby, 2000, p. 93). Some evidence does indeed suggest that teachers are able to recontextualise the tasks, strategies and approaches modeled in their mathematics methods courses to at least some degree (Ambrose, 2004; Ensor, 2001; Raymond, 1997; Schoenfeld, 1992; Thompson, 1992). Beliefs about mathematics, rather than more pedagogically related beliefs, seem to relate more strongly to subsequent classroom practice, (Ambrose, 2004; McGinnis, Kramer, Roth-McDuffie, Watanabe, 1998; Raymond, 1997; Thompson, 1992) and hence form the main focus of the beliefs examined in the current study.

While volatility of beliefs remains a concern, "early and continued reflection about mathematics beliefs and practices, beginning in teacher preparation, may be the key to improving the quality of mathematics instruction and minimizing inconsistency between beliefs and practice” (Raymond, 1997, p. 574).

\section{Existing Instruments}

Instruments to assess teacher content knowledge for teaching have been developed (Hill, Schilling \& Ball, 2005), but these measures do not address beliefs, nor are they designed to give formative feedback to teachers. While these measures do address details of particular content areas, they do not shed light on the ways in which the mathematical knowledge may be understood, unpacked or developed by individuals, the details of how such understanding might be enhanced in teacher training programs, or the role of reflection and evolving beliefs. Thus the lack of measures of teachers' content knowledge may be a difficulty in determining what features of preservice education and later professional development contribute to teacher learning (Hill et al., 2004).

Similarly, measures exist related to student as well as teacher beliefs (for example, McGinnis et al., 1998; Ross et al., 2003; Tapia \& Marsh, 2004), but these measures have not generally been studied specifically with preservice teachers nor do they explicitly connect to teacher knowledge or values about mathematics itself. We need measures which examine and unpack (Adler et al., 2005; Ball et al., 2000) different types of mathematical knowledge such as procedural and conceptual knowledge (McCormick, 1997), as well as the relationship of such knowledge to beliefs about the nature of mathematical thinking and beliefs about what kinds of learning should take place in mathematics classrooms (Ambrose, 2004). Additionally, ways must be found, based on adult learning principles, to provide preservice teachers with feedback about their own strengths and weaknesses in a way that motivates them to invest in deepening their own understanding; simply telling preservice teachers their mathematical understanding is "poor" will likely not have a positive or motivating effect. Some positive feedback, coupled with information that motivates them to develop areas of weakness, might be a better model.

\section{Significance for Preservice Education}

Hiebert (1999) states that instructional programs that emphasize conceptual development, with the goal of developing students' understanding, can facilitate significant mathematics learning without sacrificing skill proficiency. Similar 
programs to deepen preservice teacher understanding are also badly needed in teacher education (Adler \& Davis, 2006) where time is often at a premium.

Adler and Davis (2006) cite, for example, the general absence of evaluation tasks in teacher education programs which emphasize unpacked or elaborated mathematics for teaching and state that "this kind of mathematical work is not well understood and is hard to do in the context of formalized teacher education programs” (p. 291).

Deep mathematical understanding of the type needed by teachers of mathematics is not developed by taking a larger number of undergraduate courses in mathematics (Foss, 2000). The development of such deep understanding of fundamental mathematics is not straightforward; it requires intention, commitment, and reflection; it can be challenging but highly rewarding work for teachers.

Recent research provides evidence that teachers can learn mathematics for teaching in specially designed courses, but success varies from course to course (Hill et al., 2004). It is unclear which features of such courses are most effective.

Since preservice teachers, as other learners, come to education programs holding beliefs based on their prior experiences, and if their own experiences of learning mathematics in school consisted mostly of memorizing procedures (Ambrose, 2004) then new and deeper experiences are required. What teachers bring to the process of learning to teach affects what they learn (Ball, 1996). Important features of successful programs may be to foreground mathematical content (Hill et al., 2004) and to include rich experiences coupled with reflection (Ambrose, 2004; Ball, 1996; Schmitt \& Safford-Ramus, 2001) to enhance resiliency of new beliefs. Probing more carefully into the content of professional development courses to identify curricular variables associated with teachers' learning (Hill et al., 2004) and beliefs (Stipek et al., 2001) is necessary to determine features of successful courses and how such features support later classroom teaching practice.

\section{Purpose of Study}

Preservice education in the Canadian province of Ontario, as elsewhere, suffers from a shortage of time to support student teachers' evolving content knowledge for teaching as well as to address pedagogical issues. Hence it is crucial that this time be used as effectively as possible, and be based on research specifically about preservice teachers' needs and learning. The current study focused on investigating the mathematical understandings for teaching held by grade four to ten (junior-intermediate) teacher candidates, as well as their beliefs about mathematics and how it should be taught. Mathematical understanding was examined under the dual lenses of procedural knowledge and conceptual understanding similar to the framework used in the Ma (1999) interviews. These characteristics were examined using a written survey, and were re-examined at the end of the methods course to look for change and to probe for possible relationships. Pretest results were shared with participants at the next class, and discussion followed to support their individual reflection and goal-setting for the course. 


\section{Objectives}

Specific objectives included developing, refining and validating an instrument for assessing both preservice teacher knowledge and beliefs about mathematics, which would also be used by preservice teachers for the purpose of receiving feedback and for participants to subsequently use for self-reflection and goalsetting. Due to the shortage of available time in the current preservice program, it was desired to have the instrument require as little classroom time as possible to administer.

The following research questions were of interest:

- What relative levels of both procedural knowledge and conceptual understanding do these samples of incoming teachers of mathematics demonstrate?

- What beliefs about mathematics knowing, learning and teaching are held by incoming pre-service teachers?

- How might teachers' knowledge and beliefs evolve during a standard methods course?

\section{Method}

Data was collected in written survey form from just over 100 preservice teachers at the beginning and end of their mathematics methods courses taken in their certification year, for two years. The instrument gathers data about both beliefs about mathematics, and knowledge about elementary mathematical concepts. More specifically, the POM (Perceptions of Math) instrument examines components of mathematical knowledge based on the spirit of the Ma (1999) interviews as well as other surveys of undergraduate students (Kajander \& Lovric, 2005) and attempts to unpack this knowledge based on ideas of procedural and conceptual knowing (Byrnes \& Wasik, 1991; McCormick, 1997). The instrument also probes the types of beliefs held by participants about mathematics itself and how it should be taught and learned, based on values associated with procedural and conceptual learning (Ernest, 1989; Rittle-Johnson \& Koedinger, 2002). The most recent version of the survey, used to generate the 2005-2006 preservice data, is provided in the Appendix.

An initial version of the survey was administered in 2004-2005. The beliefs portion of the survey was revised based on item analysis after this first administration. In a parallel study with in-service teachers, the survey was subsequently administered to a sample of in-service grade 7 teachers along with other standard measures of teacher knowledge (Hill et al., 2005) and beliefs (Ross et al., 2003) providing initial validation for the new instrument with inservice teachers (see Kajander et al., 2006; Kajander \& Zerpa, 2006). The beliefs portion of the survey was then further revised and the instrument was readministered to the second sample of preservice teachers during the second year of the current study in 2005-2006.

Survey scoring was done by two graduate students working with the researcher to provide standardization, based on methods developed previously (Kajander \& Lovric, 2005). Procedural knowledge questions were scored out of two points. One point was awarded for showing the beginning of a method that could have led to a correct answer but had some flaw such as a computational 
error; two points were awarded for a solution leading to a correct answer (the quality or efficiency of the method was not accessed). Conceptual knowledge was also scored on a two point scale. Participants who were able to do any one of providing an example or story problem, model or diagram, or mathematical justification to support the calculation they had just done, received two points. An incomplete response scored one point. A reiteration of a rule (for example, “because I know two negatives make a positive”) scored no points.

\section{Results and Discussion}

The survey yielded scores in four variables. These were Procedural Values, or participant beliefs about the importance of procedural learning in mathematics (PV), Conceptual Values, or beliefs about the importance of conceptual learning in mathematics (CV), Procedural Knowledge, or demonstration of ability to find the correct answer to elementary mathematics questions (PK), and Conceptual Knowledge, or the ability to explain, model, give an example or do the question another way, in order to show understanding of how or why the method worked (CK).

Reliability of the beliefs portion of the survey at the post-test in year one using Chronbach's alpha were established at 0.78 for Procedural Values and 0.70 for Conceptual Values, and in year two using the revised survey at .78 for Procedural Values and .82 for Conceptual Values. The same questions were used at the pretest and post-test within each year's sample.

The knowledge portion of the survey remained largely unchanged from year 1 to year 2 although very slight wording changes were made, and scores were highly consistent. See Table 1 for a summary of the mean pretest scores, each shown scaled out of 10 , for the two years.

Table 1

Pretest mean scores on POM survey

\begin{tabular}{|c|c|c|c|c|c|c|}
\hline & \multicolumn{3}{|c|}{ Pretest Data 2004-2005 } & \multicolumn{3}{|c|}{ Pretest Data 2005-2006 } \\
\hline & Mean & $\mathrm{N}$ & $\begin{array}{c}\text { Std. } \\
\text { Deviation }\end{array}$ & Mean & $\mathrm{N}$ & Std. Deviation \\
\hline PV & 6.3000 & 107 & 1.32701 & 7.8910 & 111 & 1.22701 \\
\hline CV & 7.2065 & 107 & 1.25045 & 7.8324 & 111 & 1.22216 \\
\hline PK & 5.7196 & 107 & 2.27287 & 6.9730 & 111 & 2.09527 \\
\hline CK & 1.0841 & 107 & 1.59670 & 0.9730 & 111 & 1.41073 \\
\hline
\end{tabular}

\section{Discussion of pretest results}

According to the survey, the preservice teachers studied appear to have believed relatively strongly in the importance of both procedural as well as conceptual learning in their classrooms when they arrived in the methods course.

The pre-test knowledge scores are consistent with findings in other research (for example, see Ball, 1990; Ma, 1999), and once again underscore the urgency of the situation. While procedural knowledge scores might be seen to be adequate as an initial position (the survey was administered with no warning), the 
conceptual knowledge scores have a consistent mean score of about one out of a possible 10 points, or $10 \%$, each year. In fact the mode score in both years was a startling zero.

Figures 1-4 provide a few samples of student work on selected questions from the instrument. Each Figure shows the work of one student on both the pretest and the post-test. The samples of work at the pretest illustrate the quantitative data; it was found that when teachers were asked to explain how or why a method worked, they generally fell back on only explaining the steps in the procedure they used. It should be reiterated that in scoring for conceptual understanding, multiple explanations were not required; any reasonable example, justification or explanation was accepted, i.e., participants received two points if they were able to provide any plausible evidence of understanding. Examining the individual post-test work in the Figures shows that some of the work which received a full 2 points, while much improved over the pretest, might arguably still not be a "complete" explanation.

Figure 1. Student A Pretest and Post-test Response on Sample Question

Pre-test

2. $5-(-3)$

a) $5+3=8$

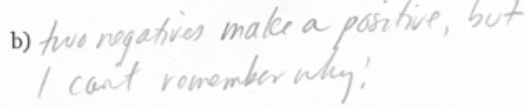

Post-test

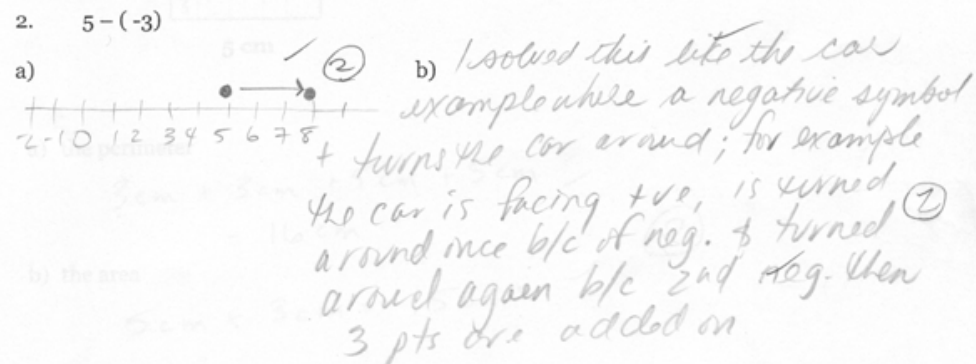

[Note: Part a) is scored as PK and Part b) as CK]

Figure 2. Student B Pretest and Post-test Response on Sample Question

Pre-test

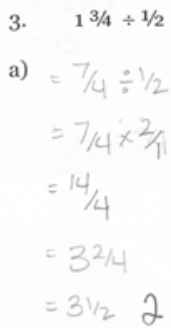

b)

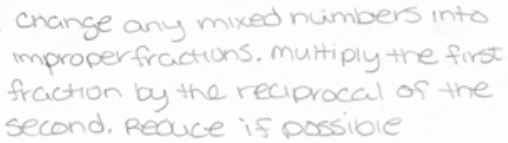


Post-test

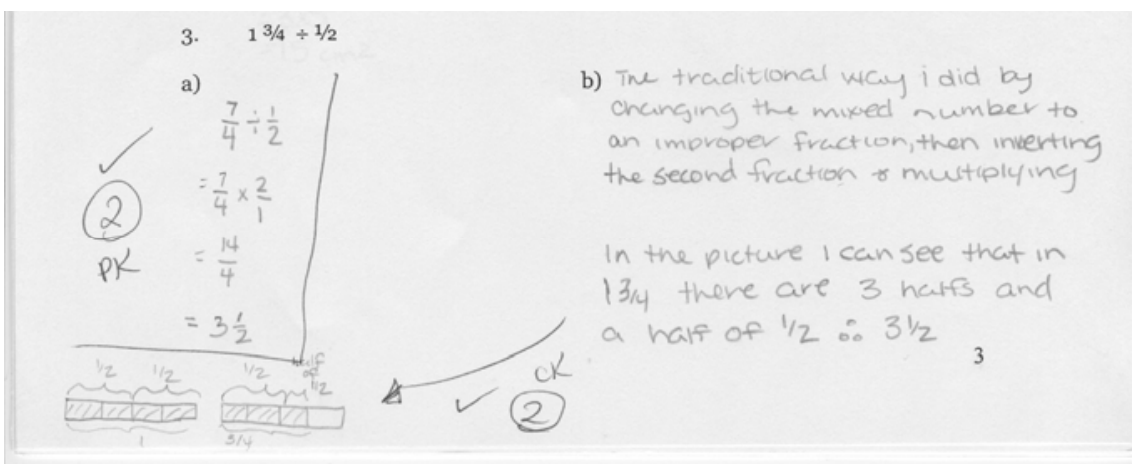

Figure 3. Student C Pretest and Post-test Response on Sample Question

Pre-test

3. $13 / 4 \div 1 / 2$

a) $1 \frac{3}{4} \div \frac{2}{4}$ b) I know how to get

$=\frac{7}{4} \div \frac{2}{4} 1 \quad \begin{aligned} & \text { acommon denominator } \\ & \text { \& thats all }\end{aligned}$

Post-test

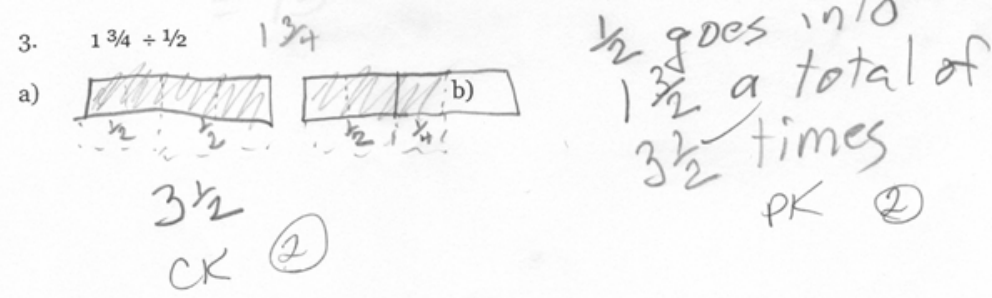

[Note: Generally Part a) is scored as PK and Part b) is scored as CK. In this case the posttest "procedure" used to generate the answer was the model, so the PK score was credited in the CK work]

Figure 4. Student D Pretest and Post-test Response on Sample Question

Pre-test

7. Is it true that as the perimeter of a rectangle increases, so does the area? Explain.

Yes, increcsing the length of the sides of a rectangle will increase the area inside

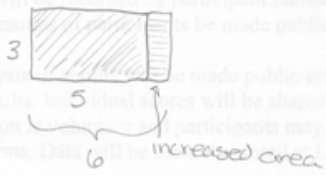


Post-test

7. Is it true that as the perimeter of a rectangle increases, so does the area? Explain.

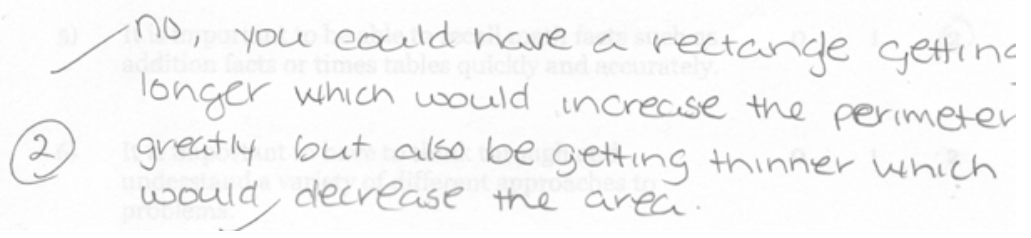

[Note: This question is scored for CK only]

If the survey questions chosen could be agreed upon as one possible subset of the ideas which might be important for intermediate teachers to know and deeply understand, then the results show that these teacher candidates were nearly unable initially to demonstrate any of the abilities cited as important by Ma and Ball in terms of understanding and unpacking mathematical ideas such as by coming up with suitable models or examples, explaining or justifying a method mathematically, or providing alternative solutions. Furthermore, the discussion and illustration of important ideas of reform in such methods courses-such as exploring how one might encourage and examine alternate mathematical models and solution methods with students-is quite ridiculous if preservice teachers are not able to effectively describe even one model. The implication for the content of methods courses for such teachers is clear: deepened mathematical understanding must be supported before discussions about reform based pedagogy have any hope of bearing fruit. As Adler, Ball, Krainer, Lin and Novotna (2005) underscore, we must further explore ways to teach both mathematics and teaching in the same program. Clearly, the mathematics itself is crucially important in the developmental process.

\section{Post-test results}

Changes were seen by the post-test in both years. Table 2 shows the post-test mean results over both years. Conceptual knowledge scores, while still lower than procedural knowledge, are shown to have increased substantially from the pretest in each year.

Table 2

Post-test mean scores on POM survey

\begin{tabular}{ccccccc}
\hline & \multicolumn{2}{l}{ Post-test Data 2004-2005 } & \multicolumn{3}{c}{ Post-test Data 2005-2006 } \\
\hline & Mean & $\mathrm{N}$ & $\begin{array}{c}\text { Std. } \\
\text { Deviation }\end{array}$ & Mean & $\mathrm{N}$ & Std. Deviation \\
$\mathrm{PV}$ & 5.4822 & 107 & 1.52834 & 6.1649 & 111 & 1.58439 \\
$\mathrm{CV}$ & 7.6505 & 107 & 1.35322 & 8.4595 & 111 & 1.36677 \\
$\mathrm{PK}$ & 7.1215 & 107 & 1.24165 & 8.4775 & 111 & 2.12708 \\
$\mathrm{CK}$ & 3.9953 & 107 & 2.83883 & 4.7838 & 111 & 2.53487 \\
\hline
\end{tabular}


Significant change was found in all four variables from the pretest to the post-test, in both years of the study, $(\mathrm{p}<.05)$ using a repeated measures t-test. Both knowledge scores increased significantly, as did conceptual values. Also of interest is the drop in procedural values. In other words by the end of the year participants generally answered the survey by rating somewhat lower the items related to the importance of focusing on procedural learning, for example requiring students to demonstrate fluency in set methods, in their own classrooms - see Tables 3 and 4 . This might be considered to be consistent with a shift towards reform based beliefs.

Table 3

T-test between pre and post for each dependent variable (CK, PK, CV, PV) 2004-2005

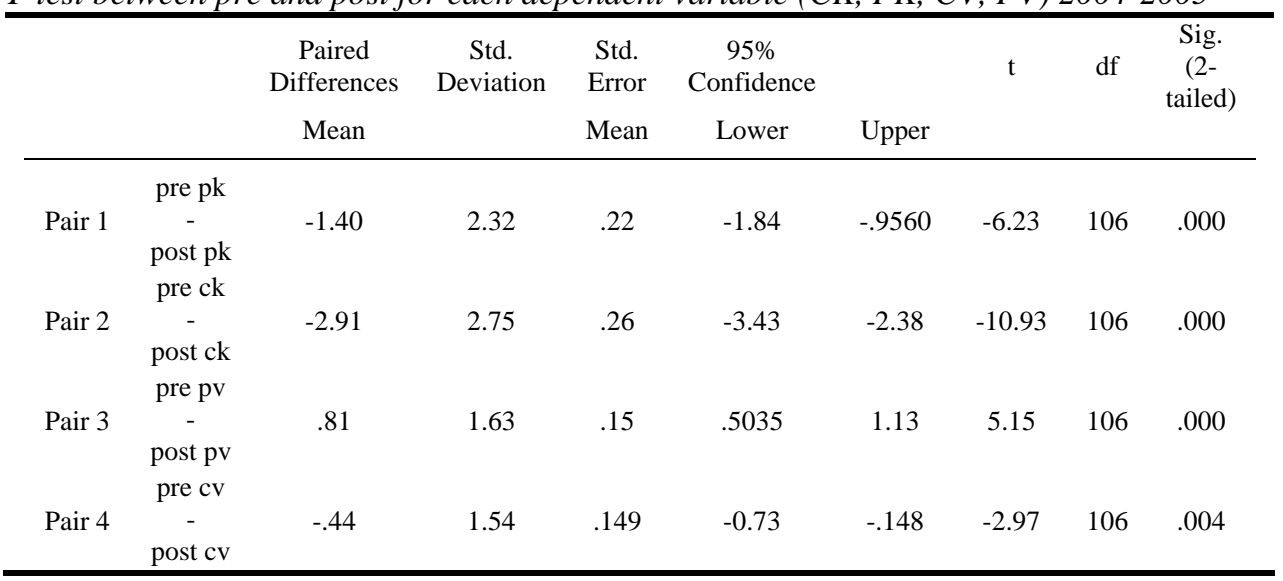

Table 4

T-test between pre and post for each dependent variable (CK,PK,CV, PV) 2005-2006

\begin{tabular}{|c|c|c|c|c|c|c|c|c|c|}
\hline & & $\begin{array}{c}\text { Paired } \\
\text { Differences } \\
\text { Mean }\end{array}$ & $\begin{array}{c}\text { Std. } \\
\text { Deviation }\end{array}$ & $\begin{array}{l}\text { Std. } \\
\text { Error } \\
\text { Mean }\end{array}$ & $\begin{array}{c}95 \% \\
\text { Confidence } \\
\text { Lower }\end{array}$ & Upper & $\mathrm{t}$ & df & $\begin{array}{l}\text { Sig. } \\
\text { (2- } \\
\text { tailed) }\end{array}$ \\
\hline Pair 1 & $\begin{array}{c}\text { pre pv } \\
- \\
\text { post pv } \\
\text { pre cV }\end{array}$ & 1.72 & 1.47 & .140 & 1.44 & 2.00 & 12.3 & 110 & .000 \\
\hline Pair 2 & post cV & -.62 & 1.50 & .143 & -.91 & -.34 & -4.38 & 110 & .000 \\
\hline Pair 3 & $\begin{array}{c}\text { pre pk } \\
- \\
\text { post pk } \\
\text { pre ck }\end{array}$ & -1.50 & 2.32 & .22 & -1.94 & -1.06 & -6.82 & 110 & .000 \\
\hline Pair 4 & post ck & -3.81 & 2.66 & .25 & -4.31 & -3.30 & -15.04 & 110 & .000 \\
\hline
\end{tabular}

Figures 1-4 also show the post-test response for selected questions for four sample students. Examining these responses shows some change in students' arguments; answers attempt to use models and diagrams, and explain why the method makes sense or what is happening. Teachers generally showed some 
evidence of their attempts to make sense of these methods by the post-test, although a number of the explanations were incomplete.

\section{Discussion}

Results provided from the current study appear to support Hill and Ball's (2004) claim that mathematical understanding for teaching can be increased by a single course experience. However, I would argue that the post-test level of conceptual understanding demonstrated by many participants according to the current instrument is still highly inadequate for classroom teaching, and that more time must be allowed for such learning by preservice teachers if they are to teach effectively.

Questions on the beliefs portion of the POM survey were carefully crafted so that it would be possible to be simultaneously high in both procedural values and conceptual values without self-contradiction. For example, participants might agree both with the statement "Accurate and efficient calculation skills are highly important in mathematics" (procedural values) and with the statement "It is important to develop connections between related ideas and models in mathematics" (conceptual values). It is interesting to note that even so, procedural values dropped significantly during both years of the study, while conceptual values rose. This may be indicative of a shift toward the kind of beliefs often associated with reform based teaching, and away from more traditional beliefs. It may be interesting to note that the deepened interest in conceptual understanding seemed to also be accompanied by a willingness to relax more traditional or procedural goals.

In a related study of in-service grade 7 teachers using a slightly different version of the same instrument (Kajander et al., 2006; Kajander \& Zerpa, 2006), a significant drop was also seen in procedural values as well as a significant increase in conceptual values, after intensive mathematics-based training. These beliefs changes accompanied a significant increase in knowledge of Number and Operation content as measured by the Content Knowledge for TeachingMathematics (CKT-M) middle school instrument of Hill et al. (2005). While at this point we can not pinpoint the exact reasons for these changes, some consistency of results is being observed; as preservice (and inservice) teachers deepen their understanding, their beliefs about the value of conceptual learning appear to be enhanced, while their concern with the learning of procedural methods appears to diminish. It could be conjectured that such changes might accompany a shift towards a more reform-based conception of mathematics learning. As teachers claim to want to focus more on deep understanding in their classrooms as well as being able to demonstrate deeper understanding themselves, it appears they may also state more willingness to rethink some of their previously held goals in mathematics learning such as focusing strongly on procedural learning. Given that classroom teachers face many day to day decisions relating to use of time, their beliefs will ultimately influence their classroom teaching decisions. For example, a teacher observing students solving problems in a hands-on manner in her classroom will have to decide at what point (if ever) to draw the class together and suggest a standard method, or whether to continue to invest time in student investigation and a sharing of alternate student generated methods, which, while they may ultimately deeply 
enhance understanding and encourage meaningful generalisation, may or may not be the most efficient for developing computational fluency.

While the newly evolved beliefs of the preservice participants in the study were indeed situated initially in a preservice program, recommendations from the literature were considered in the design of the methods course. The mathematics content itself was forgrounded (Hill \& Ball, 2004), activities were grounded as much as possible in classroom practice (Boaler, 2000), experiences to support changed beliefs about mathematics were provided (Ball, 1996; Raymond, 1997; Schoenfeld, 1992; Thompson, 1992), and extensive self-reflection was encouraged (Ball, 1996; Raymond, 1997). Participants with low conceptual knowledge (CK) scores who espoused believing in conceptual learning at the pretest $(\mathrm{CV})$ were encouraged to reflect on their own scores and set goals for their own learning; most participants immediately reflected that deepening their understanding had to be a major goal for them in the course.

An examination of the subsequent classroom practices of the teachers involved in this project would add to this research, and this process has in fact begun. An initial interview and classroom visit to one first year teacher from the current study whose knowledge and beliefs shifted by a more than typical amount during the methods course according to the instrument, showed significant evidence of enacted beliefs and practices as supported by the goals of the methods course. Further work is on-going and appears promising.

\section{Recommendations}

\section{Developing effective preservice mathematics classroom environments}

It is argued that teachers' initially weak conceptual understanding and high valuing of conceptual learning could potentially shape and define their choices of developmental goals, as supported by principles of adult learning theory (Schmitt et al., 2001). A powerful experience after coming to see this personal need is to feel the excitement of "really understanding" a piece of mathematics deeply (often for the first time), which can be very pleasurable (Schmitt et al.). Preservice teachers' self-reflection about their initial capacity, followed closely by an experience in deepened conceptual understanding, might have the potential for a powerful effect on participants and may encourage the decision to continue to invest strongly in deepening their conceptual knowledge in subsequent mathematical content areas. This development might then also be reflected in later instrument scores. As participants' mathematical power increases, so does their valuing of this type of learning, thus reinitiating the cycle.

In my own experience working with preservice teachers, I have found that their passionate desire to make their classrooms better places for childrens' learning is a powerful motivator for their own learning. Continually situating preservice mathematics classroom experiences as much as possible in the context of childrens' classroom learning, and reflecting on such learning, may have the potential to deepen mathematical understanding and change teachers' beliefs about mathematics. While participants tend to initially have a restricted view of the subject typically based on the notion that mathematics is largely about using procedures to generate correct answers, relating their own preservice classroom 
experiences to their own deep learning of fundamental mathematics, and reflecting on such examples as sites for future student learning, appears to support an initial shift in beliefs about mathematics itself. Teachers begin to see mathematics as a tool for thinking about ways to solve new problems which require deep understanding of concepts rather than simply consisting of poorly understood algorithms learned by rote. Such rich learning can be intrinsically enjoyable and motivating for adults (Schmitt et al., 2001) and needs to be provided at the preservice level.

Concerns about the extent and resiliency of the shift in beliefs remains. Preliminary evidence indicates that it may be possible for some new teachers to recontextualise (Ensor, 2001) their new conceptions to their own classroom work, and teachers may also continue to develop their beliefs through further effective professional development (Kajander \& Zerpa, 2006). Situating the preservice mathematics learning in terms of childrens' deep learning of the mathematics, and insisting on teacher self-reflection, may be important aspects of the teacher development process.

\section{Limitations}

Since the main researcher in this study was the course instructor, a limitation may be that participants' answers on the post-test were influenced by perceptions about the instructor's beliefs. However, participants were very aware of the coding system used to ensure anonymity; hence we attempted to minimize this effect.

Due to time limitations, the survey needed to be short. Hence the knowledge questions were few, and may not be fully representative of knowledge areas needed for teaching. Further study may be needed with an expanded topic list.

\section{Conclusions}

This study adds to other largely US studies that illustrate preservice elementary teachers' inadequate understandings of mathematics for teaching. Preservice intermediate teachers in the current study were shown to arrive at their mathematics methods course demonstrating little ability to model, explain, justify or provide an alternate method for mathematical procedures they were able to do, and these results were very consistent over a two year period.

After participating in a methods course which focused directly on conceptual knowledge of mathematics for teaching, substantial improvements were seen for many participants in conceptual understanding, according to a written instrument. However, this understanding was still far from adequate even for fundamental ideas such as basic operations with whole numbers, fractions, decimals, and integers, as well as basic measurement and patterning relationships.

Shifts were also seen in participant beliefs, which appeared to evolve to a more reform based or problem solving based conception overall. By the end of each year's course, preservice teachers seemed to be less concerned with teaching traditional procedures and even more interested in supporting deep student understanding. Such outcomes might be thought of as desirable goals for a reform based mathematics teacher education program, and thus the instrument 
might potentially provide a vehicle for preservice instructors to use in gauging their own growth as teacher educators.

Further study is needed to investigate how more enhanced growth can be facilitated for teacher candidates during their teacher training programs and elsewhere, in order to more fully prepare them for high quality classroom mathematics teaching. As well, the resilience of the newly developed beliefs needs further study. This study has attempted to suggest factors which may be important to consider in assessing preservice teacher growth and has provided a possible initial framework for such investigations.

\section{Acknowledgements}

This work was funded by the NSERC University of Manitoba CRYSTAL grant Understanding the Dynamics of Risk and Protective Factors in Promoting Success in Science and Mathematics Education.

\section{References}

Adler, J., Ball, D., Krainer, K., Lin, F., \& Novotna, J. (2005). Reflections on an emerging field: Researching mathematics teacher education. Educational Studies in Mathematics, 60, 359381.

Adler, J. \& Davis, Z. (2006). Opening another black box: Researching mathematics for teaching in mathematics teacher education. Journal for Research in Mathematics Education, 37(4), 270296.

Ambrose, R. (2004). Integrating change in prospective elementary school teachers' orientations to mathematics teaching by building on beliefs. Journal of Mathematics Teacher Education, 7, 91-119.

Ball, D. L. (1990). Prospective elementary and secondary teachers' understanding of division. Journal for Research in Mathematics Education, 21(2), 132-144.

Ball, D. (1991). Research on teaching mathematics: Making subject matter knowledge part of the equation. In J. Brophey (Ed.), Advances in Research on Teaching: Vol. 2, Teachers' Subject Matter Knowledge and Classroom Instruction (pp.1-48). Greenwich, CT: JAI Press.

Ball, D. L. (1996). Teacher learning and the mathematics reforms: What we know and what we think we know. Phi Delta Kappan, 77(7), 500-508.

Ball, D. L. (2000). Bridging practices: Intertwining content and pedagogy in teaching and learning to teach. Journal of Teacher Education, 51(3), 241-247.

Ball, D. L. (2003). Mathematical Proficiency for all Students: Toward a Strategic Research and Development Program in Mathematics Education. Santa Monica, CA: RAND Mathematics Study Panel.

Ball, D. \& Bass, H. (2000). Interweaving content and pedagogy in teaching and learning to teach: Knowing and using mathematics. In J. Boaler (Ed.), Multiple Perspectives in Mathematics Teaching and Learning (pp. 83-104). Westport, CT: Ablex Publishing.

Ball, D., Hill, H., \& Bass, H. (2005). Knowing mathematics for teaching. The American Educator. American Federation of Teachers. Retrieved November 15, 2006, from http://www.aft.org/pubs-reports/american_educator/issues/fall2005/bond.htm

Bishop, A., Clark, B., Corrigan, D., \& Gunstone, D. (2006). Values in mathematics and science education: Researchers' and teachers' views on the similarities and differences. International Journal of Mathematics Education, 26(1), 7-11.

Boaler, J. (1999). Participation, knowledge, and beliefs: A community perspective on mathematics learning. Educational Studies in Mathematics, 40, 259-281.

Boaler, J. (Ed.) (2000). Multiple Perspectives on Mathematics Teaching and Learning. Westport, CT: Ablex Publishing.

Byrnes, J. P. \& Wasik, B. A. (1991). Role of conceptual knowledge in mathematical learning. Developmental Psychology, 27(5), 777-786. 
Cooney, T. J., Shealy, B. E., \& Arvold, B. (1998). Conceptualizing belief structures of preservice secondary mathematics teachers. Journal for Research in Mathematics Education, 29(3), 306333.

Ebby, C. (2000). Learning to teach mathematics differently: The interaction between coursework and fieldwork for preservice teachers. Journal of Mathematics Teacher Education, 3, 69-97.

Eisenhart, M., Borko, H., Underhill, R., Brown, C., Jones, D., \& Agard, P. (1993). Conceptual knowledge falls through the cracks: Complexities of learning to teach mathematics for understanding. Journal for Research in Mathematics Education, 24(1), 8-40.

Ensor, P. (2001). From preservice mathematics teacher education to beginning teaching: A satudy in recontextualizing. Journal for Research in Mathematics Education, 32(3), 296-320.

Ernest, P. (1989). The knowledge, beliefs and attitudes of the mathematics teacher: A model. Journal of Education for Teaching, 15(1), 13-33.

Foss, D. (2000). Conceptions of mathematics teaching and learning: Middle level and secondary preservice teachers. Paper presented at The Annual Meeting of the American Educational Research Association, New Orleans, LA.

Guskey, T. R. (2000). Evaluating Professional Development. California: Corwin Press Inc.

Guskey, T. R. (2003). Professional Development That Works. Phi Delta Kappan, 84(10), 748-767.

Hiebert, J. (1992). Learning and teaching with understanding. In D. Grouws (Ed.), Handbook of Research on Mathematics Teaching and Learning (pp. 65-97). New York: Macmillan.

Hiebert, J. (1999). Relationships between research and the NCTM Standards. Journal for Research in Mathematics Education, 30(1), 3-19.

Hill, H. \& Ball, D. (2004). Learning mathematics for teaching: results from California's mathematics professional development institutes. Journal for Research in Mathematics Education, 35(5), 330-351.

Hill, H. C., Schilling, S. G., \& Ball, D. L. (2005). Developing measures of teachers' mathematics knowledge for teaching. Elementary School Journal, 105(1), 11-30.

Hill, H., Rowan, B., \& Ball, D. (2005). Effects of teachers' mathematical knowledge for teaching on student achievement. American Education Research Journal, 42(2), 371-406.

Hoyles, C. (1992). Mathematics teaching and mathematics teachers: A meta-case study. For the Learning of Mathematics, 12(3), 32-44.

Hoyles, C. (2002). From describing to designing mathematical activity: The next step in developing a social approach to research in mathematics education? Educational Studies in Mathematics, 46, 273-286.

Kajander, A. (2004). Ways of seeing: Unexpected student solutions and subsequent teacher responses. Proceedings of the $26^{\text {th }}$ Annual Meeting of the North American Chapter of the International Group for the Psychology of Mathematics Education. Toronto: University of Toronto.

Kajander, A. (2005). Moving towards conceptual understanding in the pre-service classroom: A study of evolving knowledge and values. Proceedings of the 27th ${ }^{\text {th }}$ Annual Meeting of the North American Chapter of the International Group for the Psychology of Mathematics Education, Roanoke, VA.

Kajander, A. \& Lovric, M. (2005). Transition from secondary to tertiary mathematics, McMaster University experience. International Journal of Mathematics, Science and Technology, 36(23), 149-160.

Kajander, A. Keene, A, Siddo, R., \& Zerpa, C. (2006). Effects of Professional development on intermediate teachers' knowledge and beliefs related to mathematics. Programming Remediation and Intervention in Mathematics. Research Report. Ontario Ministry of Education. $\quad$ Retrieved July 7, 2006, from http://www.curriculum.org/lms/files/prism/PRISMreportNWO.pdf

Kajander, A. \& Zerpa, C. (2006). Effects of in-service for middle school teachers using multiple instruments related to knowledge and beliefs. Proceedings of the $28 t h^{\text {th }}$ Annual Meeting of the North American Chapter of the International Group for the Psychology of Mathematics Education, Merida, Mexico.

Kiely, R., Sandmann L., \& Truluck, J. (2004). Adult learning and the pursuit of adult degrees. New Directions for Adult and Continuing Education, 103, 17-30. 
Lloyd, G. \& Wilson, M. (1998). Supporting innovation: The impact of a teacher's conceptions of functions on his implementation of a reform curriculum. Journal for Research in Mathematics Education, 29(3), 248-274.

Loucks-Horsley, S. (1996). Professional development for science education: A critical and immediate challenge. In R. Bybee (Ed.), National Standards and the Science Curriculum (pp. 83-95). Dubuque, IA: Kendal/Hunt Publishing Co.

Loucks-Horsley, S., Love, N., Stiles, K., Mundry, S., \& Hewson,P. (2003). Designing Professional Development for Teachers of Science and Mathematics. Thousand Oaks, CA: Corwin Press.

Ma, L. (1999). Knowing and Teaching Elementary Mathematics. Mahwah, NJ: Lawrence Erlbaum.

McCormik, R. (1997). Conceptual and procedural knowledge. International Journal of Technology and Design Education, 7, 141-159.

McDougall, D., Lawson, A., Ross, J., MacLellan, J., Kajander, A., \& Scane, J. (2000). Research Report: A study on the Impact Math implementation strategy for the Ontario Mathematics Curriculum, Grades 7 and 8. OISE/UT (158).

McGinnis, J.R., Kramer S., Roth-McDuffie A., \& Watanabe T. (1998). Charting the Attitude and Belief: Journey of Teacher Candidates in a Reform-Based Mathematics and Science Teacher Preparation Program. Retrieved July 7, 2006, from http://www.towson.edu/csme/mctp/Research/AERA98.html

Raymond, A. (1997). Inconsistency between a beginning elementary teacher's mathematics beliefs and practice. Journal for Research in Mathematics Education, 28(5), 555-576.

Rittle-Johnson, B. \& Koedinger, K. (2002). Comparing instructional strategies for integrating conceptual and procedural knowledge. Proceedings of the $24^{\text {th }}$ Annual Meeting of the North American Chapter of the International Group for the Psychology of Mathematics Education, 969-978, University of Georgia.

Ross, J. McDougall, D., Hogaboam-Grey, A., \& LeSage, A. (2003). A survey measuring elementary teachers' implementation of Standards-based mathematics teaching. Journal for Research in Mathematics Education, 34(4), 344-363.

Ruffell, M., Mason, J., \& Allen, B. (1998). Studying attitude to mathematics. Educational Studies in Mathematics, 35, 1-18.

Schmitt, M. J. \& Safford-Ramus, K. (Eds.). (2001). Adults Learning Mathematics: A Conversation between Researchers and Practitioners. Masseteusis: Harvard Graduate School of Education.

Schoenfeld, A. (1983). Beyond the purely cognitive: Belief systems, social cognitions and metacognitions as driving forces in intellectual performance. Cognitive Science, 7, 329-363.

Schoenfeld, A. (1985). Mathematical Problem Solving. New York: Academic Press.

Schoenfeld, A. (1992). Learning to think mathematically: Problem solving, metacognition, and sense making in mathematics. In D. Grouws (Ed.), Handbook of Research on Mathematics Teaching and Learning (pp. 334-370). New York: Macmillan.

Schommer-Aikins, M., Duell, O., \& Hutter, R. (2005). Epistomological beleifs, mathematical problem solving beleifs, and academic performance of middle school students. The Elementary School Journal, 105(3), pp. 290-304.

Skott, J. (2001). The emerging practices of a novice teacher: The roles of his school mathematics images. Journal of Mathematics Teacher Education, 4, 3-28.

Star, J. (2005). Reconceptualizing procedural knowledge. Journal for Research in Mathematics Education, 36(5), 404-411.

Stipek, D., Givvin, K., Salmon, J., \& MacGyvers, V. (2001) Teachers' beliefs and practices related to mathematics instruction. Teaching and Teacher Education, 17, 213-226.

Tapia, M. \& Marsh, G.E. (2004). An Instrument to Measure Mathematics Attitudes. Retrieved July 7, 2006, from http://www.rapidintellect.com/AEQweb/cho25344l.htm

Thompson, A. (1992). Teachers' beliefs and conceptions: A synthesis of the research, In D. Grouws (Ed.), Handbook of Research on Mathematics Teaching and Learning (pp. 127-146). New York: Macmillan. 


\section{APPENDIX \\ Perceptions of Mathematics "POM” Survey}

Research has shown that the prior ideas and understandings about mathematics that are brought to classrooms by teachers are very important in terms of how teachers will decide to teach mathematics. It is important to honestly assess what your current understanding is, in order to move forward as a teacher. This survey will have no bearing whatsoever on any course grades or evaluations, but rather will help you make some decisions about how to best focus your learning. You will have an opportunity to reassess yourself at the end of the year. You may find the survey 'hard' in places at this point. This is to be expected-don't be alarmed!

Completing the survey will allow you to create your own personal mathematical 'Profile', which will give you an idea of how you understand mathematics, and how you value different types of mathematical learning opportunities. There is no 'right' answer - everyone will be different.

This year you have a chance to think about what kind of teacher of mathematics you want to become, and to move towards that goal. This survey is designed as an important first step in determining and achieving your goals.

\section{Values Questions}

Please answer these questions by circling the response, where 0 is low or poor or disagree, and 3 is high or positive or agree. Please do not add other responses such as "not sure"-choose the closest response to your feeling.

1) It is important to me to be able to get the correct answer to math questions.

2) It is important to me to really understand how

0 and why math procedures work.

3) It is important for everyone to be able to accurately do basic math calculations such as addition or multiplication, without a calculator.

4) Everyone needs to deeply understand how and such as addition facts or times tables quickly and accurately. 
6) It is important to have to think through and understand a variety of different approaches to problems.

7) It is the teacher's job to teach the steps in each new math method to the students before they have to use it.

8) There are often several correct ways to get a right answer.

9) Accurate and efficient calculation skills are highly important in mathematics.

10) It enriches student understanding to have to think about different ways to solve the same problem.

11) It is important to practice on many familiar shorter math questions in school.

12) It is important to develop connections between related ideas and models in mathematics.

13) Most people learn math best if they are taught the methods step by step.

14) When I'm learning math I really want to know "how" and "why" the methods and ideas work.

15) Calculators shouldn't be used too much in school because they can lessen opportunities to practice computational skills.

16) Children learn deeply by investigating new types of problems different from ones they've seen before.

17) There is usually one best way to write the steps in a solution to a math question.

18) Most people learn math best if they explore problems in small groups to discuss and compare different approaches. 
19) Learning to follow "the steps" to generate

20) It is important to develop connections between ideas by working on multi step problems.

\section{Mathematics Questions}

\section{For questions 1 to 3 below on this page:}

PART a): Answer the questions, showing your steps as needed to illustrate the method you used.

PART b): Explain what you can about why and how the method you used in a) works, using explanations, diagrams, models, and examples as appropriate. If possible, do the question another way.

1. $1.6 \times 3$

a)

b)

2. $5-(-3)$

a)

b)

3. $13 \frac{1}{4} \div 1 / 2$

a)

b)

4. Find and state the pattern rule that relates $\mathrm{n}$ and the result.

$\begin{array}{cc}\text { n } & \text { result } \\ 1 & 4 \\ 2 & 9 \\ 3 & 16 \\ 4 & 25\end{array}$


5. For the rectangle below, calculate

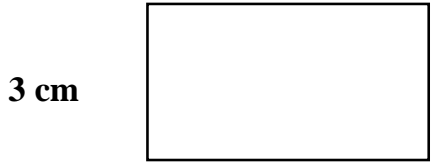

\section{$5 \mathrm{~cm}$}

a) the perimeter

b) the area

6. State up to 3 different forms of an algebraic pattern rule for the number of tiles in each diagram below (depending on the frame number), which you would mark as correct if they were submitted by a student. Use $n$ as the frame number. (The diagrams show the first 3 terms of the pattern).
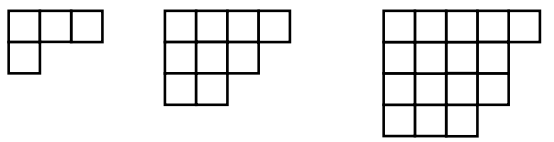

\section{a) \\ b) \\ c)}

7. Is it true that as the perimeter of a rectangle increases, so does the area? Explain. 